\title{
Domain-specific Knowledge in Lexicography: How It Helps Lexico- graphers and Users of Accounting Dictionaries Intended for Communi- cative Usage Situations
}

\begin{abstract}
Dictionaries are consulted when translating specialized texts in the global marketplace and when such texts are written in a foreign language. However, studies of translation in e.g. accounting indicate that most dictionaries do not provide the help needed in communicative situations, because they do not take into consideration that domain-specific meanings are culture- and structure-dependent. It is proposed that this state of affairs can be improved by studying the relevant types of knowledge required of lexicographers making accounting and other specialized dictionaries: declarative, procedural and schematic knowledge. These knowledge types are relevant when lexicographers select entry words as well as when they select equivalents and translations. Finally, it is proposed that declarative, procedural and schematic knowledge is needed when writing definitions of terms, and that these types of knowledge should also be reflected in the definitions presented to users or in other ways in dictionaries.
\end{abstract}

\section{Introduction}

Translation work in the field of accounting has increased exponentially during the last two decades. Accounting and other financial reporting texts contain information about business enterprises that is helpful when they need money to expand, either through borrowings from lenders such as banks (loan financing) or through investments in ownership shares (equity financing). When they decide to lend or invest, lenders and potential owners base their decisions, in whole or in part, on the available financial reports issued by the enterprises vying for money. In an attempt to develop a level playing field for actors in the global marketplace, a substantial framework of international financial reporting standards has been put in place, which all business enterprises listed on stock exchanges in the European Union have to follow (European Commission 2012). This means, inter alia, that the originally English standards have been translated into all official EU languages as well as into the languages of other countries who have adopted the standards, e.g. Brazil, Japan and Turkey (International Accounting Standards Board 2013). During this process, which is still going on as new standards are issued, translators rely on various aids, including specialized dictionaries.

One of the main challenges in translating the international standards and other financial reporting texts is to successfully bridge several gaps. Not only do translators and accounting experts have to bridge a linguistic gap, but they also have to bridge a cultural and a structural gap within the domain of accounting. According to studies carried out by Aisbitt/Nobes (2001), Baskerville/ Evans (2011), Dahlgren/Nilsson (2012), Doupnik/Richter (2002) and Evans (2004) these three bridges have to be crossed in order to achieve acceptable and successful translations, but most of the accounting dictionaries examined only cross one of these bridges, predominantly the linguistic one (see also Nielsen/Mourier 2005: 90-92). The challenge for lexicographers is, therefore, to make dictionaries that provide help to bridge all three gaps so that translators and accounting ex-

\footnotetext{
* Sandro Nielsen

Department of Business Communication

School of Business and Social Sciences

Aarhus University

Jens Chr. Skous Vej 4

DK-8000 Aarhus C

sn@asb.dk
} 
perts can cross them. This paper provides an introduction to the different types of knowledge required by compilers of specialised dictionaries, an analysis of the factual knowledge needed for selecting lemmas and equivalents, as well as the factual knowledge required for writing definitions in a set of online accounting dictionaries.

\section{Different types of knowledge are required}

In order to meet the needs of translators and accounting experts who require help to translate between two languages and communicate across borders in a foreign language, lexicographers should consider the types of knowledge that can assist them in compiling dictionaries. Compilers of accounting dictionaries intended to provide help in communicative usage situations, i.e. in connection with ongoing or planned acts of communication, should consider which types of knowledge they need in order to be able to produce lexicographic tools - whether printed or electronic - that can provide the help users require. As indicated above, linguistic knowledge can only bring lexicographers to a certain point in their quest to help translators and accounting experts, an issue that is accentuated by Baskerville and Evans (2011: 7) who argue that "Translators have to have excellent knowledge of both source and target languages but also of both accounting subcultures." The need for linguistic as well as factual knowledge is vital in translating International Financial Reporting Standards (IFRSs) from English into other languages, as a two-step process has been adopted:

Because IFRSs are technical, and the language is very precise, it is not enough simply to translate. Therefore for each language we create a committee of accounting experts and a translation becomes official only when that committee has reviewed and approved of it. (Creighton 2008: 9)

It seems that Creighton regards translation as an exercise in linguistics, whereas Baskerville/Evans (2011: 10) and Evans (2004: 225) claim that translation of accounting texts is difficult, because it is not translation of a general or standard language: accounting language is a highly specialized variety of a standard language, not only with regard to terms but also with regard to style and conventions. This view also applies to domains other than accounting and in this context the legal domain, which shares many elements with accounting (e.g. statutory frameworks and rules within the sub-fields of company law and tax law) is a case in point (Joseph 1998). In connection with definitions in legal dictionaries, Harris and Hutton (2007: 223) describe their view on the limitations of linguistic knowledge in relation to language usage as a source for lexicographers:

\footnotetext{
It is not the professional grammarian or lexicographer who has a superior ('scientific') view of how words function in social praxis and the lay person who is ignorant or perverse on that subject, but the other way round. Or, to put the point somewhat differently: although not everyone is a lawyer, everybody is a linguist - not only graduates with a doctorate in 'linguistics'. (Emphasis in original)
}

This view may not be shared by everyone, but it underlines the need for involving specialists in dictionary projects on specific domains such as accounting and law. This point is brought home by Béjoint (1988: 363), who argues that "If one wants to be sure to capture all the semantic traits of scientific or technical words, the only option is to ask specialists of the domain to define them." However, the use of specialists as arbiters in lexicographic matters may be questioned. Riggs (1989) discusses the complementarity of lexicography and terminology and describes an attempt to establish the correct terminology for lexicographic terms and concepts. The term multi-word lexical unit has several synonyms and in order to find out how the term was used, a questionnaire was distributed to the readers of the DSNA Newsletter, which is the newsletter of Dictionary Society of North America. Briefly stated, 60 readers responded of which 41 indicated that they used the term. The majority said that they used it in the sense "idiom", which is surprising since many multi-word lexical units are not idioms, whereas 4 said they used it in the sense lexeme, even though most lexemes are graphic words. Of the 41 who used the term, 7 also used the synonym compound lexical unit and 4 used compound lexical item, despite the fact that many compounds are written as one word. 10 respondents preferred the term fixed phrase, 7 used set phrase, and 3 
used lexicalised phrase, even though Riggs claims that these are not real synonyms and should be distinguished on denotative and connotative grounds. Finally, 18 respondents indicated that they never used the term, and 9 claimed that they did not know the term multi-word lexical unit (Riggs 1989:101-103). This account shows the risk lexicographers run if they choose to involve specialists: depending on which specialists you ask, you may get conflicting answers. So, one lesson to be learnt from this experience is that lexicographers, if they are not experts in a specific domain themselves, should select their specialists with care.

The question is which types of knowledge the compilers of general and specialized dictionaries should possess. There are different approaches to the study of knowledge and hence different definitions usually rooted in specific contexts, including inferential, non-inferential, propositional, virtual, social, observational, perceptual, religious, moral, scientific and clairvoyant knowledge from the field of epistemology (see e.g. Audi 2003). Ford (2012) offers a definition of knowledge in the context of understanding in relation to university programmes that seems to be better suited for lexicographic purposes, since it is directly related to theoretical and practical situations that require academic-based experience:

Knowledge is defined here as what is considered to be true, or certain (as opposed, for example, to un-
substantiated beliefs). You can know: that something is so (declarative knowledge); how something is
or can be done (procedural knowledge); and why something is so (schematic knowledge). (Ford 2012:
10. Emphasis in original)

Accounting shares many traits with the legal field so an example from the domain of law may illustrate some of the types of knowledge lexicographers need. Even though it is a general monolingual dictionary, Collins COBUILD Advanced Dictionary contains legal words and terms since they are necessary to satisfy its lexicographic functions. In connection with the lemma trial in the sense 'formal meeting in a court of law', a box with the following text is located beside and directly addressed to the entry word, or lemma:

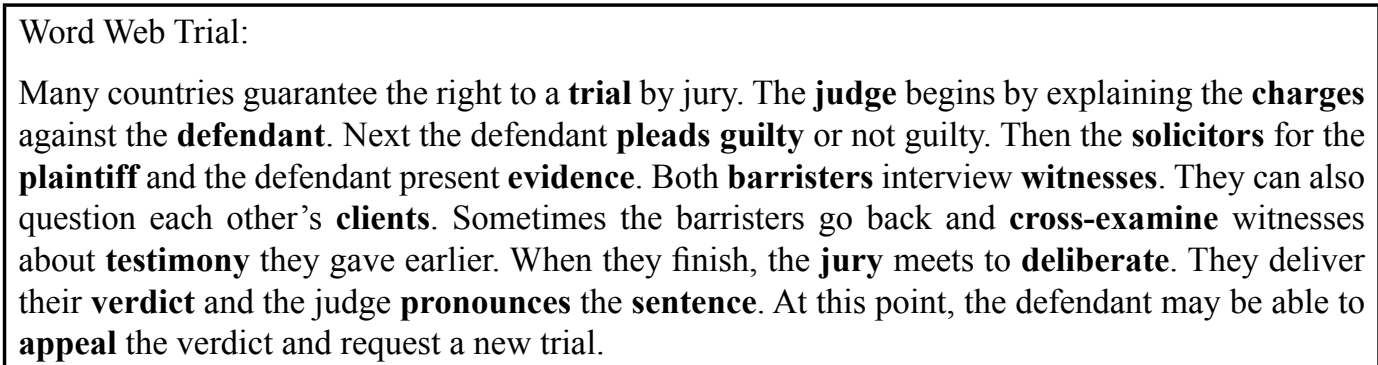

Figure 1. Word Web for trial in Collins COBUILD Advanced Dictionary (Emphasis in original)

The article is further supported by a box of word partnerships containing the following adjective + noun compounds: civil trial, fair trial, federal trial, speedy trial, upcoming trial. The purpose of these two boxes is to "present topic-related vocabulary through encyclopedia-like readings" and to "show high-frequency word patterns" found in the Bank of English corpus, respectively (Hands 2009: viii). The Word Web and the Word Partnership boxes are thus intended to help dictionary users gain further knowledge about the lemma trial.

By studying the Word Web box, we get an indication of which types of knowledge lexicographers need to compile dictionaries and which types they need to present to users. The first sentence in Figure 1 is uncontroversial and sets the stage; if we relate the data to that in the Word Partnership box we can conclude that the text concerns civil trials and not criminal trials, as only the former appears in the list of word partnerships. The second sentence contradicts that impression, since charges are only presented against defendants in criminal trials; a point that is corroborated by the third sentence, as defendants only plead guilty or not guilty in criminal cases. This 
is immediately contradicted by the fourth sentence, because plaintiffs appear in civil trials, never in criminal trials. The fourth sentence introduces solicitors as legal representatives of the parties, but this is at odds with the information in the fifth sentence, which introduces another type of legal representative, namely barristers. The terms solicitor and barrister are used in England and Wales, but not in, for instance, the USA (Ellliott/Quinn 2011: 210), so this box apparently deals with geographically restricted vocabulary and does not inform users of this fact (However, the Word Partnership box includes the term federal trial, which is relevant in the USA but not in England and Wales). Moreover, if barristers act for parties in legal trials, solicitors play no role in the trial and therefore cannot present evidence.

On the basis of the two data boxes examined above, it is possible to identify three types of knowledge required by compilers of dictionaries in respect of domain-specific words and terms. Firstly, lexicographers need to know what the words or terms mean (declarative knowledge), i.e. have knowledge that can be used as definitions or can answer the question: What is this term or concept? Declarative knowledge will ensure that lexicographers do not place plaintiffs in criminal trials. In addition, this type of knowledge will also make it clear that the term plaintiff was replaced in England and Wales by the term claimant in 1999 (Elliott/Quinn 2011: 521). Secondly, lexicographers need to know how the real life concepts behind the words or terms work (procedural knowledge), i.e. their function or role, so that they can answer questions such as: What does it do? How does it work? Knowing the roles of solicitors and barristers in civil and criminal proceedings will enable lexicographers to explain the functions of these two actors and to know that solicitors do not present evidence at trial if barristers are acting for the parties; similarly, lexicographers will know that defendants only plead guilty or not guilty in criminal cases. Thirdly, lexicographers need to know the relationships between the words and terms (schematic knowledge), e.g. that solicitors and barristers are two distinct types (coordinate concepts) of lawyers (superordinate concept). This knowledge will provide an answer to a question such as: How does this term or concept relate to that term or concept? These findings support the claim by Béjoint (1988: 357) that "The concepts designated by scientific and technical words are 'specialized', in the sense that they can only be mastered if one has a thorough knowledge of the domain." The above types of knowledge are necessary for the selection of lemmas and equivalents as well as for writing definitions and may be considered basic knowledge requirements of lexicographers.

\section{Domain-specific knowledge and selection of lemmas and equivalents}

The value and usefulness of dictionaries depends, to a large extent, on the lemmas selected. The value and usefulness of translation dictionaries within a specific domain also depends on the equivalents selected. Bergenholtz/Tarp (1995: 98) point out that the process of selecting sourcelanguage lemmas and target-language equivalents requires "meticulous, goal-oriented selection" performed by lexicographers as well as subject-field specialists. Such a process was adopted in the compilation of a set of monolingual and bilingual accounting dictionaries covering the languages Danish, English and Spanish, collectively referred to below as 'the accounting dictionaries' (Fuertes-Olivera et al. 2012; Nielsen et al. 2010). One of the main factors affecting the selection of lemmas and equivalents is the translation difficulties involved because these "are increased by the fact that legal language is a highly technical version (or register) of the respective standard language, with regard to lexicon and style [.....]. The same applies to accounting language" (Evans 2004: 225). The fact that accounting language has its own peculiar lexicon resulted in the selection of single-word and multi-word lexical units as lemmas and these represent several parts of speech: adjectives, adverbs, nouns and verbs, including phrasal verbs.

\subsection{Selection of lemmas}

The selection of lemmas was based on three electronic and three printed text corpora, one for each language. The largest corpora are the English ones, containing more than 4 million words, as Eng- 
lish is the lingua franca of accounting and covers three variants: international English (as used in the IFRSs), British English, and American English. The corpora are extended on an ongoing basis to keep up with the dynamics of accounting terminology (Fuertes-Olivera/Nielsen 2011) and the development in national and international accounting. However, dictionary compilers working with text corpora are unlikely to find all relevant lemma candidates due to lacunae in corpora and lack of factual knowledge. In order to solve these problems, the lexicographers involved in the compilation of the accounting dictionaries make up a team of accounting specialists and lexicographic specialists. In this context, lexicographic specialist means someone with extensive theoretical and practical experience in evaluating, planning, and making lexicographic products as well as conducting research related to lexicographic products; and accounting specialist means someone with extensive theoretical and practical experience in accounting work and research in accounting matters. This interdisciplinary team of lexicographers ensures that, inter alia, relevant terms and collocations are selected, and that definitions and equivalents are factually correct. In rough numbers, the English Accounting Dictionary, the Danish Accounting Dictionary, the English-Danish Accounting Dictionary, the Danish-English Accounting Dictionary and the EnglishSpanish Accounting Dictionary each contains well over 6000 lemmas representing the forms of lexical units and parts of speech described above. Furthermore, each dictionary contains more than 20,000 collocations and phrases and between 1,000 and 2,000 competence examples (for a detailed description of the dictionaries, see Fuertes-Olivera/Nielsen 2012: 204-205; and Nielsen/ Almind 2011: 151-154).

The selection of lemmas presented challenges at various levels. Firstly, so-called semi-technical or mixed terms, i.e. terms that are formally identical with words from the everyday vocabulary but which have special meanings in accounting, must be selected in order to ensure comprehensive lexicographic coverage. From a terminological point of view, it is not the word or term that is special but the meaning of and the concept referred to by the term. According to a study carried out by Baskerville/Evans (2011: 37), concepts with a wider or different meaning in accounting compared to their meaning in everyday language constitute a specific problem area in translation. The graphic words recognition and recognise are familiar and known from the vocabulary of laypersons: accept that something is true, or realise that you have encountered something previously. These meanings are not applicable to accounting, as the relevant, domain-specific meaning is: inclusion of and to include an amount in the income statement or in the balance sheet. Without declarative and procedural knowledge of factual accounting matters, such words and terms would not be selected as lemmas.

Secondly, multi-word lexical units are difficult to identify because they can easily be mistaken for collocations and phrases. At first glance, a string of words such as other interest receivable and similar income look like a phrase, but proper accounting knowledge reveals that the string of words constitute a term that refers to an item in the income statement representing interest and other financial revenue earned by a business enterprise. Such multi-word lexical units must be selected as lemmas, because they play important roles in theoretical and practical accounting.

Thirdly, some of the purely technical terms, i.e. terms that are used exclusively in the field of accounting, have synonyms. The selection of these is particularly important in English accounting language because there may be synonyms within one accounting subculture, e.g. the British, and across accounting subcultures, as a British accounting term may be equivalent to a different American term or IFRS term. For example, the British term profit and loss account is a full synonym of the term income statement used in international as well as American accounting English; and the British terms $P \& L$ account and profit and loss statement are other full synonyms. As the lexicographers of the accounting dictionaries include accounting specialists, such synonyms are all selected because the specialists have the necessary factual knowledge. 


\subsection{Selection and presentation of equivalents}

The selection of equivalents also presented a number of challenges. Some English terms may have more than one equivalent in Danish and Spanish and in such cases users need to be told which one is the best to use, e.g. because of frequency or clarity. The English term imputed cost has the two Spanish equivalents coste de producción sin variación de efectivo and coste imputa$d o$. In order to help users translate and write factually correct texts, the lexicographers recommend the use of coste de producción sin variación de efectivo because this is preferred by Spanish accountants, and because it is more precise. The English-Spanish Accounting Dictionary gives the recommended term as equivalent and coste imputado as a synonym of the equivalent. Lexicographic decisions in such cases require a high level of factual knowledge.

In other situations, a Danish or Spanish term may have to be translated into several English terms, because the structures of Danish and Spanish accounting subcultures differ from the structures of American, British or international accounting subcultures. The Danish term afskrivning and the Spanish term amortización are conceptually equivalent and cover the systematic allocation of the cost of tangible and intangible assets over their useful lives. There is no single concept in American, British and international accounting English that has the same coverage, but two English concepts together cover the meaning of the Danish and Spanish terms, as illustrated in Figure 2.

\section{Amortización \\ I Depreciation, amortization. II \\ Redemption (of bonds).}

Figure 2. English translations of amortización in Dictionary of Accounting Terms.

The data in Figure 2 merely indicate the two English equivalents and do not inform users of the relevant subject-specific matters, namely that the English term amortization applies to intangible assets whereas the term depreciation applies to tangible assets. Translation problems like this one are aptly described by Dahlgren/Nilsson (2012: 56) who claim that "of course, the problem is not linguistic, but rather conceptual." The Danish-English Accounting Dictionary therefore gives two equivalents to the Danish term afskrivning and contains usage notes explaining the limited scope of each of the two English equivalents.

Sometimes translation problems occur as the Danish and Spanish versions of the International Financial Reporting Standards (IFRSs) seem to contain faux amis. Such instances are relevant for translation and other types of communication in accounting subcultures and need to be addressed by lexicographers. For instance, the English IFRS term government grant is translated into subvención del gobierno in the relevant IFRS standard, but the lexicographers of the accounting dictionaries decided to recommend the translation subvención official. The reason is that Spanish accountants prefer subvención official because the IFRS translation may easily be misleading in Spain where there are 17 regional governments and 1 central government. This is a type of problem described by Evans (2004: 235) where the conceptual meaning of the term government in English accounting subcultures differs from the conceptual meaning of the seemingly equivalent term gobierno in the Spanish accounting subculture. The procedure adopted by the lexicographers is in line with the recommendation by Evans (2004: 238), who argue that when finding target-language equivalents, translators, and by implication lexicographers, should "avoid the use of an existing signifier in the target language if such use could lead to confusion with an existing signified."

Another challenge was to select equivalents to English accounting terms that introduced new concepts in Danish and Spanish accounting language and culture. In a few cases, the translation strategy of language switching, also referred to as loan translation and non-translation, was 
adopted so that the English term was used as the equivalent. For example, the Danish and Spanish equivalents of the English term EBITA (the abbreviation of 'earnings before interest, tax and amortisation') are also EBITA. There are Danish and Spanish equivalent terms for the full expression, but the English abbreviation is used almost exclusively in Danish and Spanish accounting and this was the decisive factor in this situation. In other cases, the translation strategy of circumlocution was adopted so that the Danish and Spanish equivalents of English terms consisted of descriptive re-writings using more words than the English terms.

In some instances, the translation strategy differed depending on language. The English term damages is rendered skadeserstatning in Danish, whereas the Spanish term is indemnización por daños y perjuicios. The English term production-volume variance refers to a new concept so here the translation strategy coinage, i.e. creating a new word in the target language, is also available. The Danish accounting specialists came up with the Danish term produktionsafvigelse and a descriptive equivalent, afvigelse fra det planlagte niveau for omfanget af produktionen, of which the latter is the more precise; the Spanish accounting specialists recommended the descriptive equivalent variación en la tasa predeterminada de distribución de costes indirectos de fabricación. These solutions square well with the findings reported by Baskerville/Evans (2011: 49-50) who investigated the strategies adopted by translators of IFRSs into EU languages: "Those translating into Scandinavian languages favour paraphrasing and circumlocution. The Romance language family also favour those techniques as well as adding additional notes." Not only do lexicographers have to possess basic domain-specific knowledge when selecting lemmas and equivalents but also when finding and writing definitions.

\section{Domain-specific knowledge and definitions}

Many dictionaries contain so-called general definitions, i.e. definitions intended to apply to the largest possible number of situations. The result is that, inter alia, compilers strive to write explanations of words and terms that have general referential foci to their objects and this is problematic when lexicographers write definitions intended for every situation and for everybody. The distinction between definitions in general and specialized dictionaries is clearly described by Harris/Hutton (2007: 212):

\footnotetext{
The problem for the general lexicographer, who purports to be giving definitions for the total inventory of words in languages like English and French, is that the technique so successfully deployed in restricted domains such as physics and chemistry cannot be extended to general vocabulary. And the reason is not the absence of anything corresponding to the periodic table for other areas of human inquiry. The reason is that words have no general referential focus, nor even anything that approximates to one: the very idea is self-contradictory. Focus implies the deliberate exclusion, from a particular communicational context or type of context, of all facts deemed irrelevant thereto. Generalized focus makes no more semantic sense than private property belonging to no one. (Emphasis in original)
}

In order to avoid writing definitions for everybody and nobody, lexicographers may consider making dictionaries that present definitions targeted to specific user types. In this context, the term definition is not used in the sense found in disciplines such as philosophy or logic but in a strict lexicographic sense (see Wiegand 1992), and it is proposed that a lexicographic definition is the specific set of data that explains the meaning of a lemma and which is clearly addressed to the lemma. This is also referred to as a lexicographic meaning description (Svensén 2009: 214).

Lexicographers have often tried to determine what the best or correct lexicographic meaning explanation looks like and several approaches have been suggested, for example the lexical definition, the conceptual definition, the relational definition, the extensional definition, and the intensional definition (Fuertes-Olivera/Arribas-Baño 2008: 49-50). However, lexicographers may not be able to find one correct type of definition, because "The notion of a definition adequate to all occasions and all demands is a semantic ignis fatuus" (Harris/Hutton 2007: 49). One interpretation of this statement is that a lemma may be explained in more than one way depending on whom the intended readers are and the specific situation in which the definition is intended to be 
used. Generally speaking, potential and actual users of specialized dictionaries can be described as laypersons, semi-experts and experts (e.g. Nielsen 1990: 131; Bergenholtz/Tarp 1995: 19-22). Since general-language dictionaries contain words from specialized domains and registers, this distinction may be relevant for all dictionaries. The intended user groups of the accounting dictionaries are (1) translators and language staff, (2) accounting experts and semi-experts, and (3) students and laypersons interested in Danish, English and Spanish accounting matters. The members of these user groups have different factual, linguistic, production and translation competences and definitions written for accounting experts would be too difficult to understand by most of the intended users. Therefore, the definitions have been written so that they represent fairly the meanings of the terms as defined by accounting experts and so that they meet the factual needs and competences of semi-experts (see e.g. Nielsen 2011: 205-209).

Important criteria in relation to the meanings of specialized terms are homonymy and polysemy. In order to find the correct meaning of a term, users must be able to identify the correct meaning of words that are spelt identically (homographs) but have different referential foci. The syntagmatic criterion 'part of speech' is used for treating terms as homonyms, so that the accounting dictionaries clearly distinguish between homographs belonging to different parts of speech, for example the noun charge ('an expense or cost') and the verb charge ('to ask for payment for goods or services'). Morphological criteria are generally used in cases of polysemy, so that homographs that can be both countable and uncountable are treated as being polysemous, such as the noun liability ('legal responsibility to pay compensation or a debt' (uncountable) and 'obligation to pay money owed to someone' (countable)). In a few cases the decisive factor is referential focus, e.g. where the meaning is subject to jurisdictional constraints: the abbreviation ISA can mean both International Standard on Auditing (IFRS) and Individual Savings Account (UK). This example is a relatively uncomplicated one, as $I S A$ refers to two very different concepts, but the writing of definitions of other homographs, for instance $C F C$, require declarative, procedural and schematic knowledge. The reason is that the difference between some homographs can only be discovered if detailed examinations are carried out at a deep structural level in the relevant subculture. The English-Danish Accounting Dictionary lemmatises the abbreviation CFC (i.e. controlled foreign company) as polysemous because it has the same general meaning in the three accounting subcultures but also three culturally specific and different definitional elements, which are important for the intended users:

1. UK definition: A CFC is a controlled foreign company in which a UK company has a $10 \%$ stake or more.

2. US definition: A CFC is a controlled foreign corporation whose voting stock is more than $50 \%$ owned by US stockholders, each of whom owns at least $10 \%$ of the voting power.

3. DK definition: A controlled foreign company is a foreign company in which a Danish parent company has a controlling interest.

In order to help translators of accounting texts, it is necessary to provide them with lexicographic meaning descriptions that are not devoid of context. Therefore, special referential focus is needed when compiling accounting dictionaries assisting in the production and translation of texts, and this is also recognized by Baskerville/Evans (2011: 34): "This [glossaries empty of context] resonates with concerns expressed in other disciplines where dictionary translations or bilingual encyclopaedias are often seen as misleading, because they do not address the fact that meanings are culture-dependent."

Many accounting terms are defined in national and international standards and should be relatively easy for specialized lexicographers to rewrite. However, some official definitions are particularly challenging. International Accounting Standard (IAS) 17 deals with the accounting of leases and contains several important definitions; for instance, the Standard defines the term operating lease as: "A lease other than a finance lease" (International Accounting Standards Board 
2005: paragraph 4). This definition is useless on its own; in order to find the meaning of the term operating lease, readers need to have the definition of finance lease at the same time. Furthermore, it is impossible to make a linguistic analysis of the above definition that will provide a proper lexicographic meaning description; only declarative, procedural and schematic knowledge of accounting matters can render a proper understanding and definition of the concept of operating leases. For the three accounting dictionaries with English lemmas, the lexicographers came up with the following definition:

\begin{abstract}
An operating lease is a lease that is not a finance lease, i.e. some of the risks and rewards connected to the ownership of the leased asset remain with the lessor, and the asset is leased for a period which is much shorter than its estimated useful life. Typically, the leased asset and the obligation to pay lease payments are not recognised in the balance sheet of the lessee, but the periodic lease payments are recognised as operating costs in the profit and loss account.
\end{abstract}

The above definition contains a presentation of data that reflect the declarative and procedural knowledge required for writing this lexicographic meaning explanation. In order to complete the picture, the lexicographers also needed to provide data representing schematic knowledge. The definition contains a reference to the term finance lease, and this reference is supplemented by an explicit indication of two antonyms of operating lease: finance lease and capital lease. So in this context the relationship of two coordinate concepts is made explicit. The above discussion of the relationship between knowledge and definitions shows that lexicographers should heed the words of Harris/Hutton (2007: 121): "It will have to suffice to say that, in an integrationist account, acquiring the concept of a 'word', in the sense in which lexicography is concerned with words, emerges as a complex and sophisticated process."

\title{
5. Concluding remarks
}

Accounting dictionaries based on a traditional, linguistic approach do not fully satisfy the needs for help accountants and translators have when translating financial reporting texts and when writing financial reporting texts in a foreign language. This state of affairs can be remedied by re-assessing the need for including the relevant types of knowledge in dictionaries and at the same time lay down basic knowledge requirements for lexicographers. The above discussion indicates that dictionary users need data that help them respond to the challenges presented by the linguistic, cultural and structural differences inherent in accounting at an international level. In order to select relevant lemmas and equivalents, and in order to write appropriate definitions, lexicographers need declarative, procedural and schematic knowledge within the field of accounting. In addition, these types of knowledge are also relevant for users, so lexicographers should include in their dictionaries data that reflect these three types of knowledge. This will ensure the making of dictionaries that provide users with help to successfully bridge the linguistic, cultural and structural gaps.

\section{References}

Aisbitt, Sally/Nobes, Christopher 2001: The true and fair view requirement in recent national implementations. In $A c$ counting and Business Research 31(2), 83-90.

Audi, Robert 2003: Epistemology. A contemporary introduction to the theory of knowledge. New York/London: Routledge.

Baskerville, Rachel/Evans, Lisa 2011: The darkening glass: Issues for translation of IFRS. Edinburgh: The Institute of Chartered Accountants of Scotland.

Béjoint, Henri 1988: Scientific and Technical Words in General Dictionaries. In International Journal of Lexicography 1(4), 354-368.

Bergenholtz, Henning/Tarp, Sven (eds.) 1995: Manual of Specialised Lexicography. The preparation of specialised dictionaries. Amsterdam/Philadelphia: John Benjamins.

Creighton, Kenneth 2008: Five questions on IFRS adoption. In INSIGHT. The Journal of the IASB and the IASC Foundation Q1/Q2, 8-9. 
Dahlgren, Jörgen/Nilsson, Sven-Göran 2012: Can Translations Achieve Comparability? The Case of Translating IFRSs into Swedish. In Accounting in Europe 9(1), 39-59.

Doupnik, Timothy S./Richter, Martin 2002: Interpretation of Uncertainty expressions: a cross-national study. In $A c$ counting Organizations and Society 28(1), 15-35.

Elliott, Catherine/Quinn, Frances 2011: English Legal System, 12th edn. Harlow: Longman.

European Commission 2012: IAS/IFRS Standards and Interpretations [online]. http://ec.europa.eu/internal market/ accounting/ias/index_en.htm (10.02.2013).

Evans, Lisa 2004: Language, translation and the problem of international accounting communication. In Accounting, Auditing \& Accountability Journal 17(2), 210-248.

Ford, Nigel 2012: The Essential Guide to Using the Web for Research. Los Angeles: Sage.

Fuertes-Olivera, Pedro A./Arribas-Baño, Ascención 2008. Pedagogical Specialised Lexicography. Amsterdam/Philadelphia: John Benjamins.

Fuertes-Olivera, Pedro/Bergenholtz, Henning/Nielsen, Sandro/Gordo Gómez, Pablo/Mourier, Lise/Niño Amo, Marta/ de los Rios Rodicio, Ángel/Sastre Ruano, Ángeles/Tarp, Sven/Velasco Sacristán, María Sol 2012: El Diccionario Inglés-Español de Contabilidad [online]. http://www.lemma.com (10.02.2013).

Fuertes-Olivera, Pedro A./Nielsen, Sandro 2011: The Dynamics of Terms in Accounting: What the construction of the accounting dictionaries reveals about metaphorical terms in culture-bound subject fields. In Terminology 17(1), 157-180.

Fuertes-Olivera, Pedro A./Nielsen, Sandro 2012: Online dictionaries for assisting translators of LSP texts: the Accounting Dictionaries. In International Journal of Lexicography 25(2), 191-215.

Hands, Penny (ed.) 2009: Collins COBUILD Advanced Dictionary. Glasgow: Harper Collins Publishers/Heinle Cengage Learning.

Harris, Roy/Hutton, Christopher 2007: Definition in Theory and Practice. Language, Lexicography and the Law. London: Continuum.

International Accounting Standards Board 2005: International Accounting Standard 17 - Leases. London: International Accounting Standards Committee Foundation.

International Accounting Standards Board 2013: The move towards global standards [online]. http://www.ifrs.org/Usearound-the-world/Pages/Use-around-the-world.aspx (10.02.2013).

Joseph, John E. 1998: Why Isn’t Translation Impossible? In Hunston, Susan (ed.), Language at Work: Selected Papers from the Annual Meeting of the British Association for Applied Linguistics held at the University of Birmingham, September 1997. Clevedon: Multilingual Matters, 86-97. (British Studies in Applied Linguistics, 13).

Nielsen, Sandro 1990: Contrastive Description of Dictionaries Covering LSP Communication. In Fachsprache/International Journal of LSP 3-4/1990, 129-136.

Nielsen, Sandro 2011: Function- and user-related definitions in online dictionaries. In Kartashkova, Faina I. (ed.), Ivanovskaya leksikografischeskaya shkola: traditsii i innovatsii [Ivanovo School of Lexicography: Traditions and Innovations]: A Festschrift in Honour of Professor Olga Karpova. Ivanovo: Ivanovo State University, 197-219.

Nielsen, Sandro/Almind, Richard 2011: From Data to Dictionary. In Fuertes-Olivera, Pedro A./Bergenholtz, Henning (eds.), e-Lexicography: The Internet, Digital Initiatives and Lexicography. London/New York: Continuum, 141167.

Nielsen, Sandro/Mourier, Lise 2005: Internet accounting dictionaries: present solutions and future opportunities. In Hermes. Journal of Linguistics 34, 83-116.

Nielsen, Sandro/Mourier, Lise/Bergenholtz, Henning 2010: Danish Accounting Dictionary; Danish-English Accounting Dictionary; English Accounting Dictionary; English-Danish Accounting Dictionary. Database and design Richard Almind [online]. http://www.ordbogen.com (10.02.2013).

Riggs, Fred W. 1989: Terminology and Lexicography: Their Complementarity. In International Journal of Lexicography 2(2), 89-110.

Spanish Translator Services 2006-2010. Dictionary of Accounting Terms Spanish-English [online]. http://www.spanish-translator-services.com/dictionaries/accounting-spanish-english/ (10.02.2013).

Svensén, Bo 2009: Handbook of Lexicography. The theory and practice of dictionary-making. Cambridge: Cambridge University Press.

Wiegand, Herbert E. 1992: Elements of a Theory towards a So-called Lexicographic Definition. In Lexicographica 8, $175-289$. 